Fifth International Conference on Sustainable Construction Materials and

Technologies. http://www.claisse.info/Proceedings.htm

\title{
EFFECTS ON STRENGTH OF CONCRETE FROM INCREMENTAL RUBBER AGGREGATE REPLACEMENT BY VOLUME \\ Istvan Pocklington ${ }^{1}$
}

Hsein $\mathrm{Kew}^{1}$

${ }^{1}$ Kingston University London, United Kingdom

\begin{abstract}
In the UK alone over 55 million waste tyres are produced each year according to the environmental agency.

To alleviate this issue, high volume applications must be found which can best utilise recycled rubber. The current project involves modification of concrete properties through rubber aggregate substitution by volume, producing rubberised concrete.

A control mix of C40 was designed and tested. A series of subsequent mixes containing either coarse, fine or mixed rubber aggregates at various percentage replacements by volume of the natural aggregate where produced. Surface treatment of Rubber aggregates included water washing, cement paste coating or Sodium Hydroxide $(\mathrm{NaOH})$ treatment. It was observed that the reduction in strength of the concrete mix very much depended on the grading of the rubber aggregate, the type of surface treatment the rubber aggregate was subject to, as well as the percentage replacement of the natural aggregate.
\end{abstract}

Keywords: Rubber, Rubberised, Concrete, Sustainability, Compressive,

\section{INTRODUCTION}

Waste recycled rubber tyres are a significant worldwide problem with hundreds of millions more being produced annually. Their disposal and management is a major environmental concern in many countries. Aesthetic problems incurred by their storage must be considered along with health concerns to a local populous. Their storage may result in significantly expanded breeding grounds for a variety of vermin and mosquitoes. Waste tyres also pose a substantial fire hazard which can result in both ground pollution and toxic fumes given off as emissions from combustion (Khaloo et al. 2008), (Elchalakani, 2015). To alleviate this issue, high volume engineering applications must be found which can best utilise recycled rubber.

Rubber particles have been used in the past (Liu et al. 2012), (Atahan \& Sevim, 2008) to increase concrete properties such as impact resistance, energy absorption and toughness whilst reducing the unit weight of the concrete. Properties such as, tensile, flexural and compressive strengths are all known to suffer as a result of increased rubber content (Atahan \& Sevim, 2008), (Eldin \& Senouci, 1993), (Gesoglu et al. 2014). Workability is also thought to reduce with increased rubber content (Khatib \& Bayomy, 1993), (Eldin \& Senouci, 1994), though not all research attests to this (Moroney, 2003). 
The objective of this study is to analyse and compare the differences between using coarse, fine or a combination of both rubber aggregates in a given mix design. The data included will range from $0-30 \%$ with data points at intervals every $5 \%$. Future data to be added aims to include a range up to $70 \%$ aggregate replacement by volume with correspondingly sized rubber particles with data points every $10 \%$.

\section{EXPERIMENTATION}

\section{Mix Design and Testing Materials}

A control mix with a target compressive strength of 40MPa designated 'Mix Design $A^{\prime}$ as displayed in table 1 was used in order to be compatible with future mixes involving the use of different rubber aggregate sizes. Sand $<4 \mathrm{~mm}$ diameter and coarse Thames Valley aggregate graded $20-12 \mathrm{~mm}$ was used, along with rubber aggregate ranging from 20-12 $\mathrm{mm}$ (although certain rubber aggregates are considered elongated in nature) as well as fine rubber ranging in size of approximately $1-4 \mathrm{~mm}$. Super Plasticiser ADVA 650 was used at a ratio of $8.57 \mathrm{ml} / \mathrm{Kg}$ of cement consistently throughout all samples.

Table 1 Concrete Mix Design

\begin{tabular}{|c|c|c|c|c|c|}
\hline \multicolumn{6}{|c|}{ CONCRTE MIX DESIGN } \\
\hline & Fine & Coarse & Water & Super & Volume \\
\hline Cement & Aggregate & Aggregate & & Plasticiser & \\
\hline $375 \mathrm{~kg}$ & $710 \mathrm{~kg}$ & $1110 \mathrm{~kg}$ & $180 \mathrm{~kg}$ & $3215 \mathrm{ml}$ & $1 \mathrm{~m}^{3}$ \\
\hline
\end{tabular}

The rubber used as a replacement for the natural aggregates in the control mix has a significantly lower density than that of its natural constituents, with a $G_{s}$ of 1.14 compared to $\mathrm{G}_{\mathrm{s}} 2.6$ for coarse and 2.7 for fine aggregates respectively. As such, it was decided to replace the natural aggregates by relative volume with their correspondingly graded rubber aggregates. Surface treatment included cement paste coating, water washing and Sodium hydroxide $(\mathrm{NaOH})$ treating as a means to improve the properties of rubberised concrete. The extent of their usage in mix designs can be categorised as a set of 8 batches, displayed on table 2 .

Table 2 Concrete batch designation based on rubber aggregates used CONCRETE MIX BATCHES

\begin{tabular}{lllll}
\hline $\begin{array}{l}\text { Aggregate } \\
\text { Size }\end{array}$ & \multicolumn{3}{l}{ Surface Treatment } \\
& & NaOH & $\begin{array}{l}\text { Cement } \\
\text { Paste } \\
\text { Coated } \\
\text { (C) }\end{array}$ & $\begin{array}{l}\text { Water } \\
\text { Washed }\end{array}$ \\
& Plain (P) & (N) & & \\
\hline
\end{tabular}




\begin{tabular}{lllll}
\hline Coarse (A) & AP & AN & AC & AW \\
\hline Fine (B) & BP & BN & - & \\
\hline Mixed (C) & CP & CN - & - \\
\hline
\end{tabular}

Abbreviated designations for concrete mixes will correspond to those given in table 2 . For instance: a mix utilising coarse, plain rubber aggregates will be designated 'Mix AP' whilst a mix using fine, sodium hydroxide treated rubber aggregates are designated 'Mix BN'.

Compressive strength tests were carried out on $100 \mathrm{~mm}$ concrete cubes at curing periods of 7, 14 and 28 days. Natural aggregates where replaced with rubber ranging from $0 \%$ (control) to $30 \%$ aggregate replacement by volume at increments of $5 \%$. Table 3 displays examples of sample coding in relation to the batch designations of table 2 .

Table 3. Sample coding examples CONCRETE SAMPLE CODING

\begin{tabular}{llll}
\hline Aggregate Size & $\begin{array}{l}\text { Rubber replacement by } \\
\text { volume }\end{array}$ & Surface Treatment & Mix Designation \\
\hline A & $0 \%$ & C & A0C \\
\hline A & $5 \%$ & W & A5W \\
\hline B & $15 \%$ & N & B15N \\
\hline C & $30 \%$ & P & C30P \\
\hline
\end{tabular}

The example of $\mathrm{C} 30 \mathrm{P}$ given in table 3 is a percentage replacement relative to the overall volume of relative constituents in the concrete mix. As such, it denotes the replacement of both $15 \%$ coarse aggregates and $15 \%$ of fine aggregates in a mix, resulting in the overall volume of rubber being relative to $30 \%$ total rubber content. This makes the quantity of rubber and expected compressive strength of the mix to be directly comparable to both coarse and fine samples coded as A30P and B30P respectively.

\section{Rubber Aggregate Preparation}

\section{Sodium Hydroxide Surface Treatment}

All surface treatments of rubber aggregates where carried out prior to their introduction to the concrete mix. The sodium hydroxide treated aggregates where prepared by immersing them in a large $400 \mathrm{~L}$ container of prepared $\mathrm{NaOH}$ solution at a concentration of $10 \% / w t$. Once the rubber was suitably treated, the $\mathrm{NaOH}$ was drained and diluted whilst the rubber was thoroughly washed for an extended period of time in 
order to remove any excess $\mathrm{NaOH}$ solution from the rubber before being left to dry. This was done to ensure both user safety when handling the rubber post surface treatment as well as to remove a variable, namely chemical reactions between $\mathrm{NaOH}$ residue and the concrete mix.

\section{Cement Paste Coating Surface Treatment}

To coat the surface of coarse rubber with cement paste, a ratio of $1 \mathrm{~kg}$ cement, $0.3 \mathrm{~kg}$ water and $1.5 \mathrm{~kg}$ of surface dry rubber was used. All components where placed in a standard concrete mixer which ran for 2-4 minutes until the rubber aggregates where thoroughly coated, leaving no visible excess cement paste. The rubber was then spread out on a plastic covered board and left to dry for 24 hours before being stored. The cement paste coasted rubber aggregates where left for a minimum of 28 days in storage prior to use. A particle density test revealed that cement paste coating the rubber aggregates increases the mass of the rubber particles, resulting in a new $\mathrm{G}_{\mathrm{s}}$ of 1.54. This $35 \%$ increase in particle density can result in significant changes in the overall volume of the concrete mix if not accommodated for in the mix design.

\section{Water Washing Surface Treatment}

Aggregates that underwent water washing where saturated in water for approximately 20 minutes and disturbed with a metal rod to dislodge surface contaminants. The water was then drained and the remaining aggregates where spread out in a sieve with apertures of $<10 \mathrm{~mm}$. They were then thoroughly washed with a hose for another 3-5 minutes. Note that the rubber aggregates could not be oven dried post washing due to laboratory health and safety requirements.

\section{TEST RESULTS AND DISCUSSION}

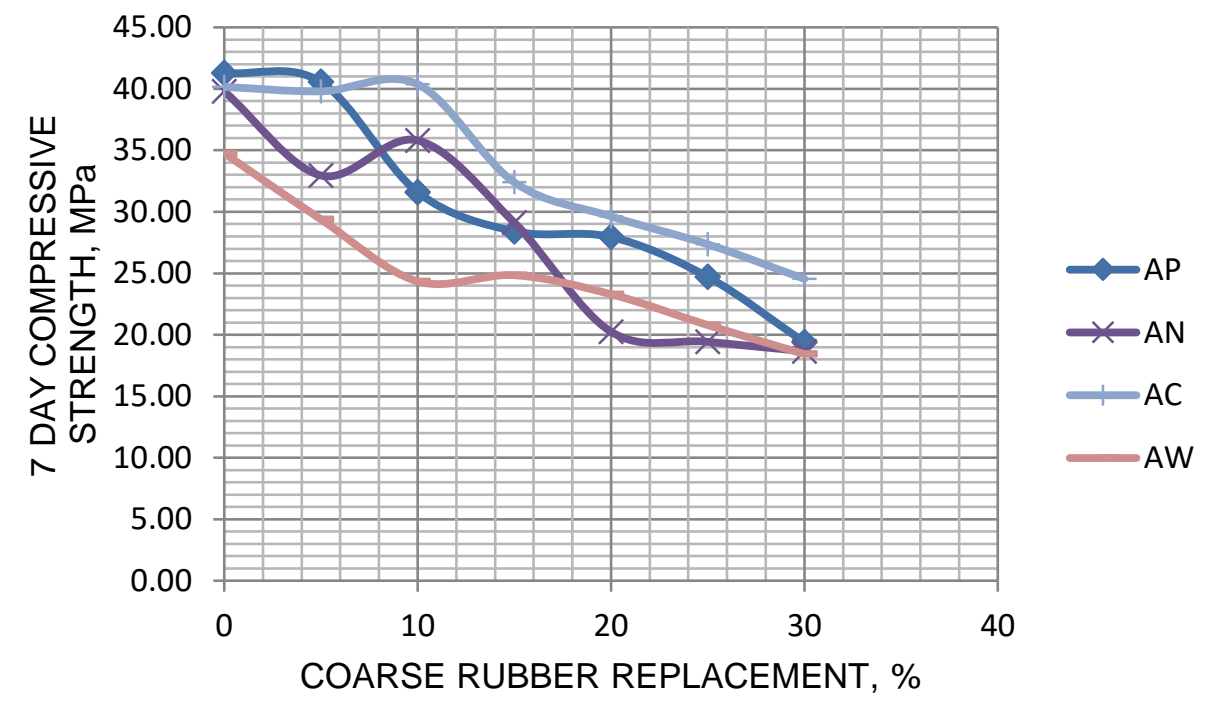

Figure 1 Effects of surface treatment on coarse rubber aggregate in concrete at 7 days 
Figure 1 shows batch $\mathrm{AC}$ providing the most promising results on average when compared to all other coarse aggregate batches. The trend continued across all days of testing, with only the control and 5\% replacement of cement paste coated aggregate yielding lower results than other coarse mixes. The increase in compressive strength can be attributed to the increased stiffness modulus between the rubber particles and the concrete matrix (Pocklington et al. 2015).

The water washed AW batch was worst performing between A0W to A15W at 7 days, however at $20 \%$ replacement onwards, it either matched or exceeded the compressive strength of the $\mathrm{NaOH}$ treated coarse aggregates at all ages (see figures 1 and 4).

At 7 days curing, plain coarse rubber batch AP performed consistently with the exception of the significant drop in compressive strength between A5P and A10P. As can be seen on figure 2, the drop in compressive strength between A5P and A10P is least at 14 days, however further developmental increase is minimal at the 28 day compressive strength test. This is most likely due to hydrocarbon contamination of the sourced coarse rubber aggregates (Pocklington et al. 2015).

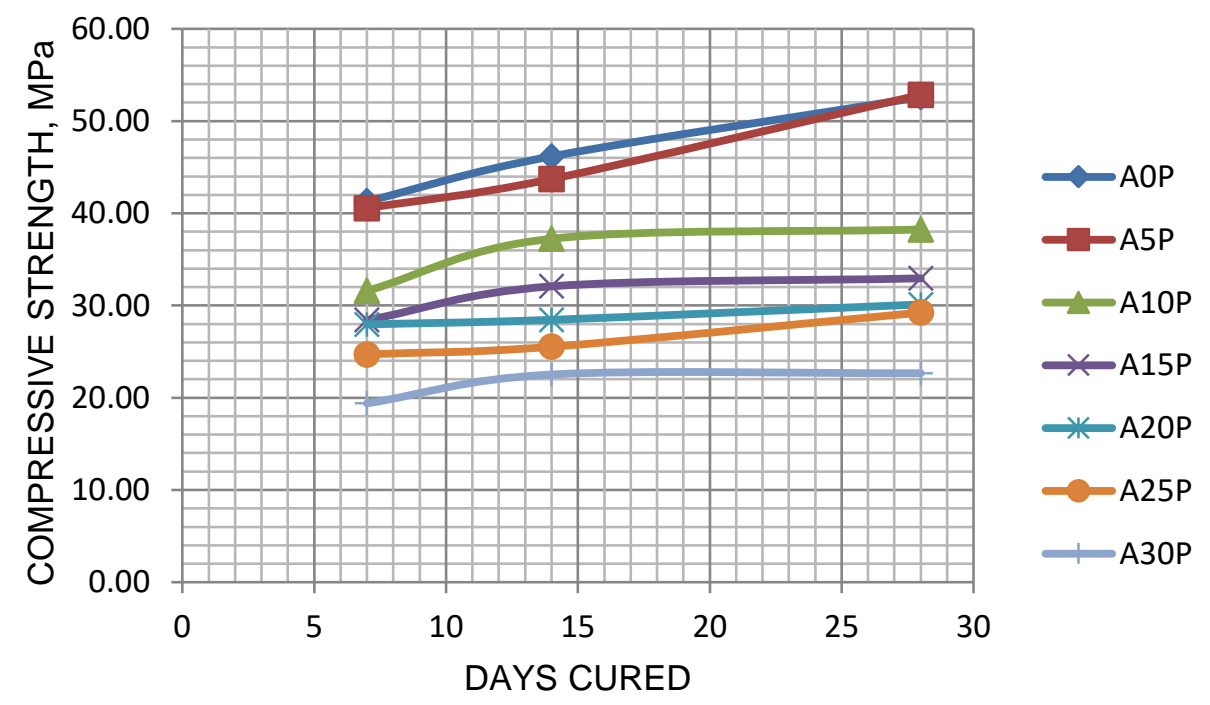

Figure 2 Developmental strength of coarse plain rubberised concrete over 28 days.

The most significant difference between plain and $\mathrm{NaOH}$ treated coarse rubber is on the 7 day test shown in figure 1. Reasons for Coarse $\mathrm{NaOH}$ treated rubber not performing as well could be due to residual $\mathrm{NaOH}$ solution on the surface of the coarse rubber aggregates influencing the hydration process of concrete. For instance, (Reddy et al. 2006) discovered that strong alkaline substances in certain instances are known to significantly retard both the initial and final setting time of concrete such as sodium bicarbonate $\left(\mathrm{NaHCO}_{3}\right)$ although others such as sodium carbonate $\left(\mathrm{Na}_{2} \mathrm{CO}_{3}\right)$ are thought to accelerate this. 


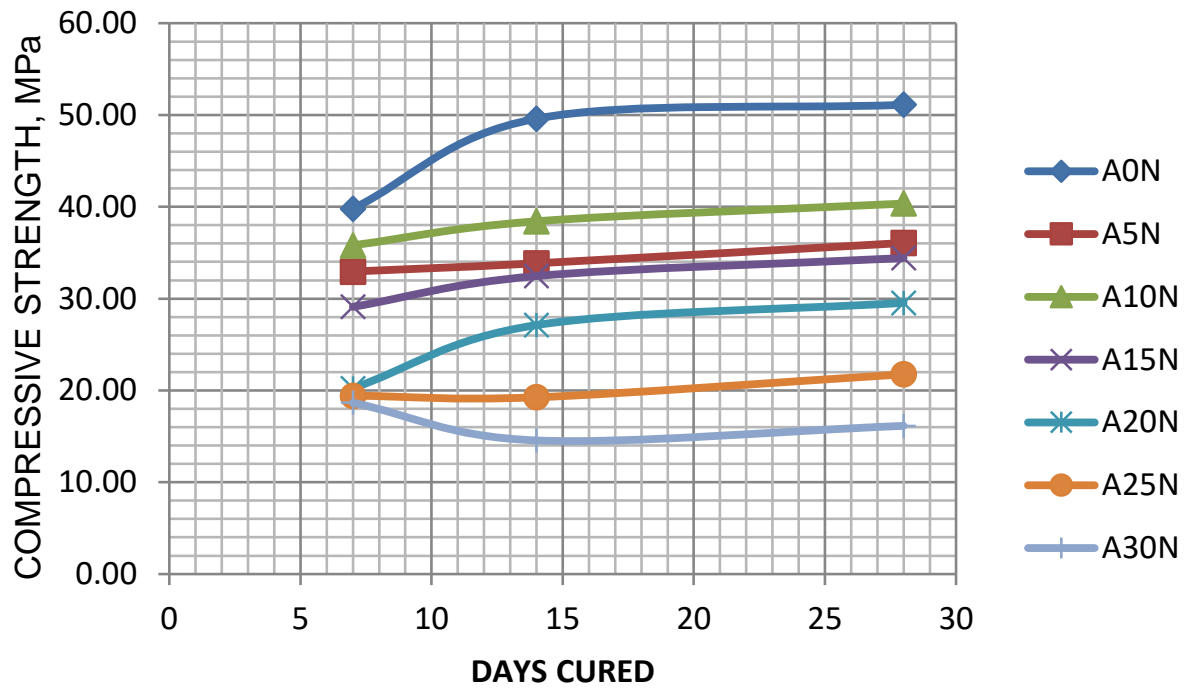

Figure 3 Developmental strength of coarse $\mathrm{NaOH}$ treated rubberised concrete over 28 days

Figure 3 shows a small, linear increase in compressive strength over time for the A5N series. Furthermore the data gathered for $\mathrm{A} 5 \mathrm{~N}$ was extremely consistent showing little variation between samples tested. As such, an explanation for the more significant drop in compressive strength at $\mathrm{A} 5 \mathrm{~N}$ shown in both figure 1 and 4 could be due to the proportion of rubber to $\mathrm{NaOH}$ residue. It is possible that the amount of $\mathrm{NaOH}$ being introduced to the concrete would have a negative effect on the compressive strength if present on the rubber particles in high enough concentration. Conversely, the etching of the rubbers surface along with the removal of other contaminants should have an increase in the compressive strength of the concrete, although an increase in this regard is not considered likely according to ( $\mathrm{Li}$ et al. 2004). At only 5\% rubber content however, any potential increase in compressive strength due to physical changes in the rubber would most likely be outweighed by the negative effects of the presence of $\mathrm{NaOH}$. 


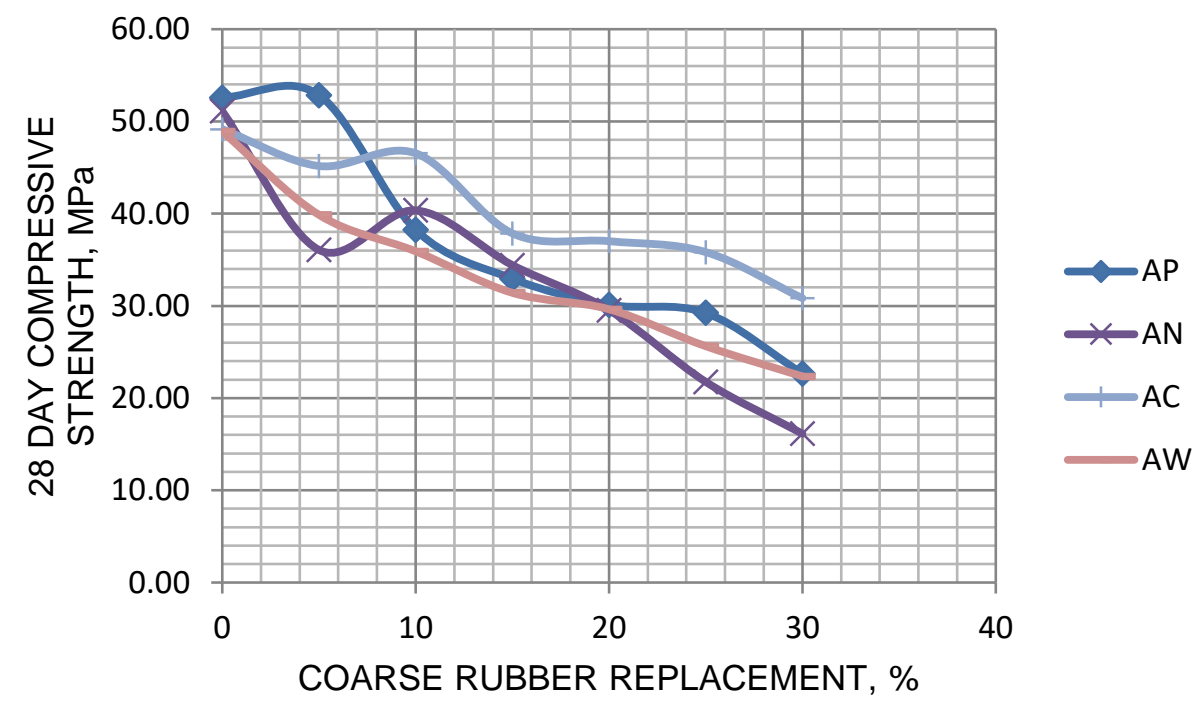

Figure 4 Effects of surface treatment on coarse rubber aggregate in concrete at 28 days

At 28 days, figure 4 shows that between 10-20\% replacement, concrete using $\mathrm{NaOH}$ treated coarse rubber can match or exceed the strength of plain coarse rubber aggregates, but not by a significant amount to justify its use when combined with it underperforming plain coarse rubber batch AP at levels of replacement both less and greater than this.

Based on Memon et al. 2013, it may be beneficial to leave some residual $\mathrm{NaOH}$ on the rubber to increase the compressive strength, but it would have to be within a molar value of $8 \mathrm{M}$ and $12 \mathrm{M}$. A $10 \%$ Solution of $\mathrm{NaOH}$ should have a molarity of approximately $2.75 \mathrm{M}$, which in itself is significantly lower than the threshold for negative influence. Whilst Memon et al. 2013 does not cover the effects of lower concentrations relative to a control, the current study has the possibility of variations of $\mathrm{NaOH}$ present on rubber particles. Whilst draining the $\mathrm{NaOH}$ solution from the container, it is possible that some $\mathrm{NaOH}$ pellets had not fully dissolved. With a reducing water level, the remaining solution may have become more concentrated, resulting in rubber at the lower levels of the container being subjected to sodium hydroxide of an increased concentration. If some solution at any time exceeded a concentration of $30 \% / \mathrm{wt}$, it would produce $\mathrm{NaOH}$ with a molarity in excess of $12 \mathrm{M}$. Due to the large scale and quantities of material involved in the manufacture of $\mathrm{NaOH}$ treated rubber for this project, this being a suitable explanation for instances of significant strength variance in compressive strength of concrete using $\mathrm{NaOH}$ treated coarse rubber aggregate merits a degree plausibility. 


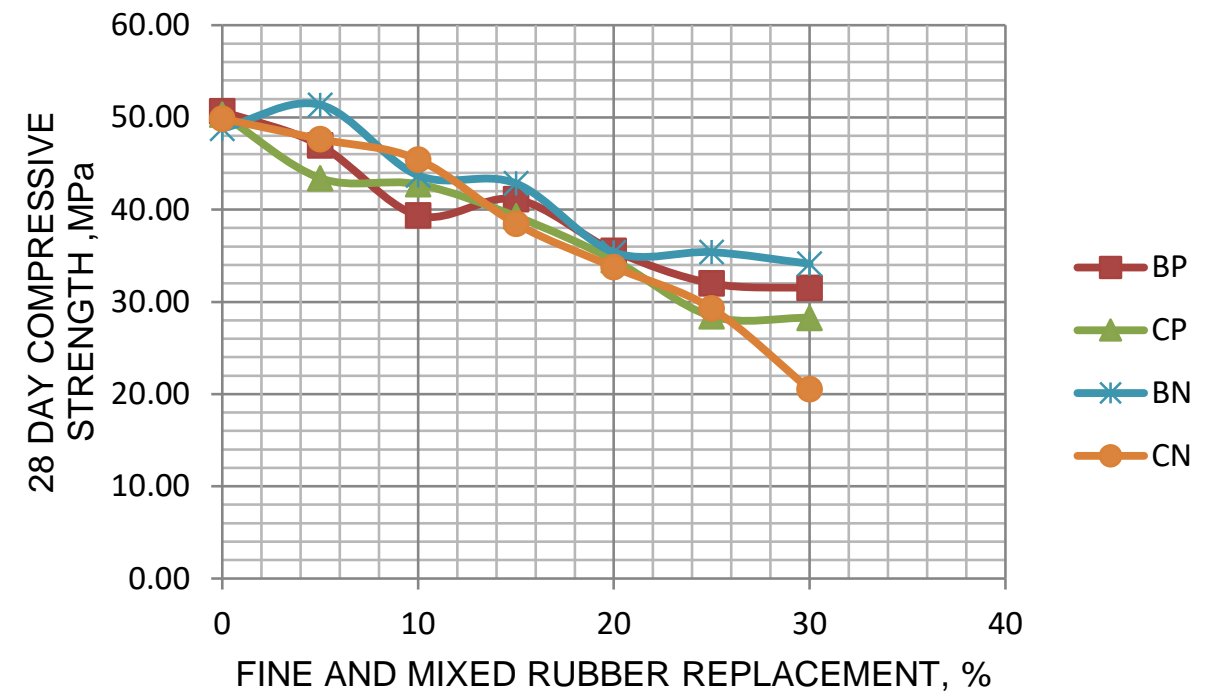

Figure 5. Effects of surface treatment on fine and mixed aggregate in concrete at 28 days

Throughout 7, 14, and 28 days, $\mathrm{NaOH}$ treated fine rubbers (BN) proved to be on average a superior mix when compared to plain fine rubbers (BP). This result is consistent with the previous findings of Li et al. 2004 as alkaline surface treatment on fine rubber proved more effective than the same treatment on coarse rubber aggregates when it came to improving their compressive strength relative to plain, untreated rubbers (Figure 5).

When both coarse and fine aggregates where present in rubber, the graphical trend of strength decline was relatively stable. This could be a result of improved grading of the rubber content, resulting in a more even distribution of rubber particles throughout the concrete matrix. Whilst mixed rubber aggregates $\mathrm{CP}$ and $\mathrm{CN}$ showed minor improvement over plain, fine mix BP at $10 \%$ replacement, they both produced weaker results from $15 \%$ onwards at 28 day strength. 


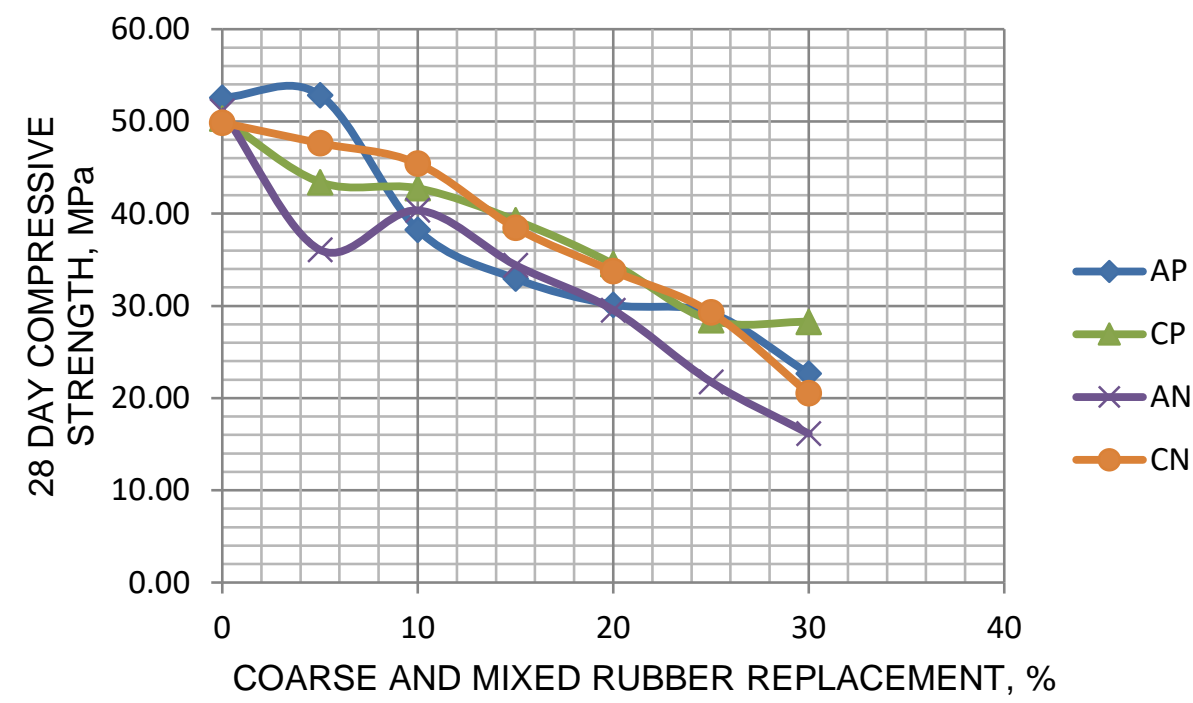

Figure 6. Effects of surface treatment on coarse and mixed rubber aggregate in concrete at 28 days

With the exception of 5\% rubber replacement, $\mathrm{CP}$ and $\mathrm{CN}$ both produced stronger results across the majority of data when compared to their coarse equivalents as shown in figure 6. At $25 \%$ and $30 \%$ replacement, they yielded similar results to AP. Again, AN did not perform well and was weaker across the whole range when compared to $\mathrm{CP}$ and $\mathrm{CN}$. Whilst the increase relative to the control of A5P could be considered an outlier in the data, a similar increase at 5\% was noted in (Ganjian et al. 2009). Furthermore BN (figure 5) also displays a minor increase in compressive strength, indicating that inclusion of rubber at low percentages has the potential to increase the compressive strength of concrete. The majority of data sets in this paper however note a consistent decline in compressive strength upon any inclusion of rubber. Negligible strength reduction supplemented by variance in the standard deviation of the control compressive strength of the mix could be considered a probable cause of this increase. More tests involving minimal natural aggregate replacement with rubber is recommended in order to clarify this. 


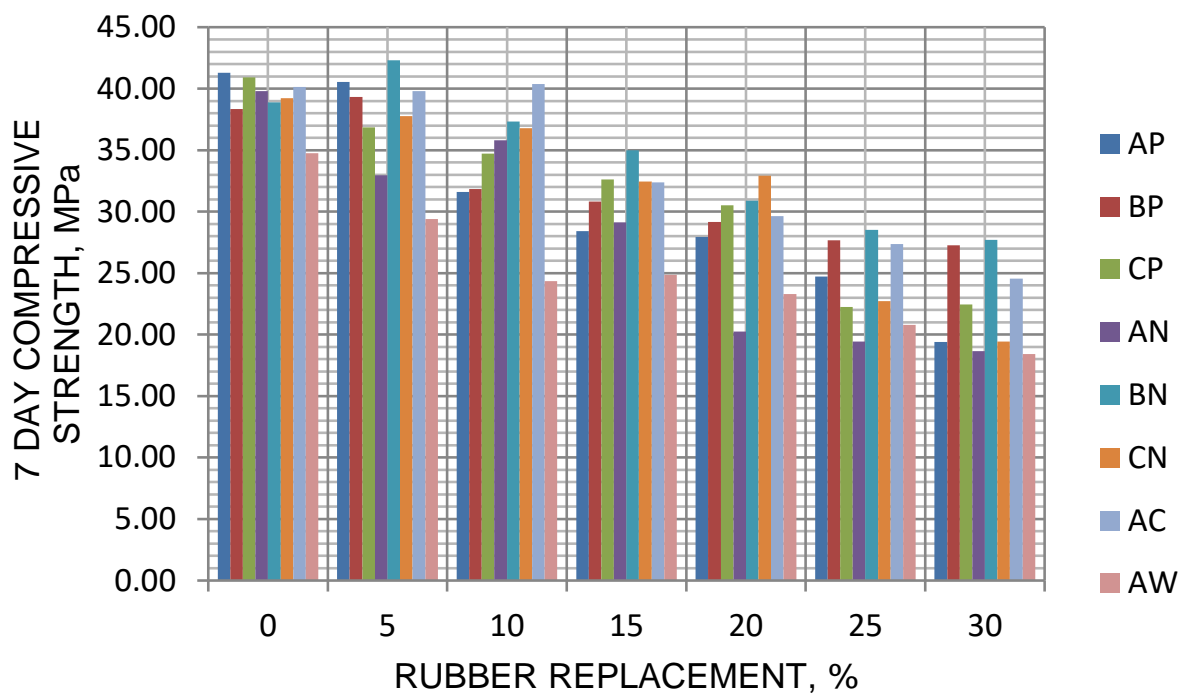

Figure 7. Influence of rubber replacement by volume on 7 day compressive strength of concrete

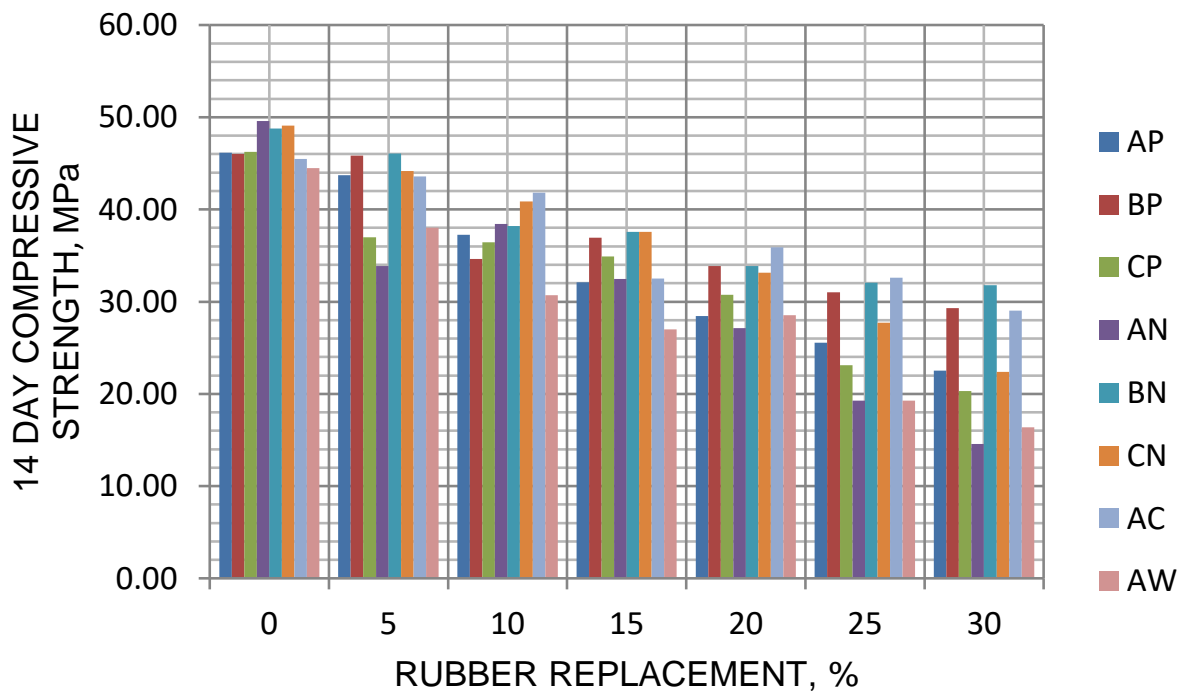

Figure 8. Influence of rubber replacement by volume on 14 day compressive strength of concrete 


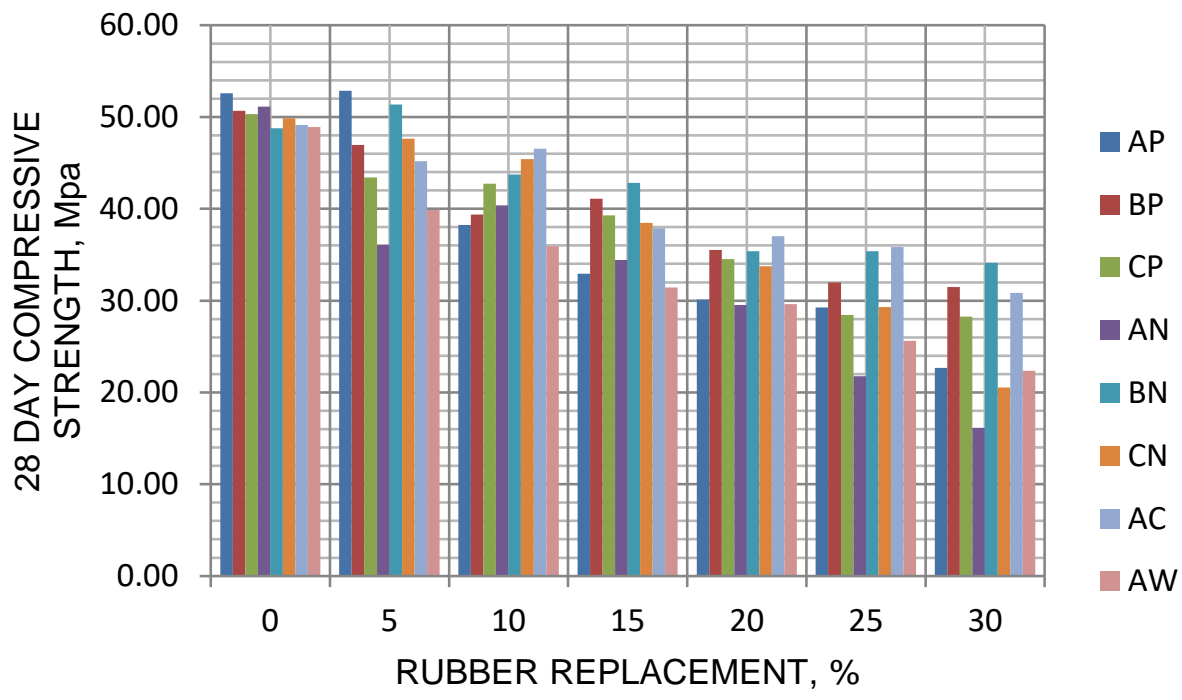

Figure 9. Influence of rubber replacement by volume on 28 day compressive strength of concrete

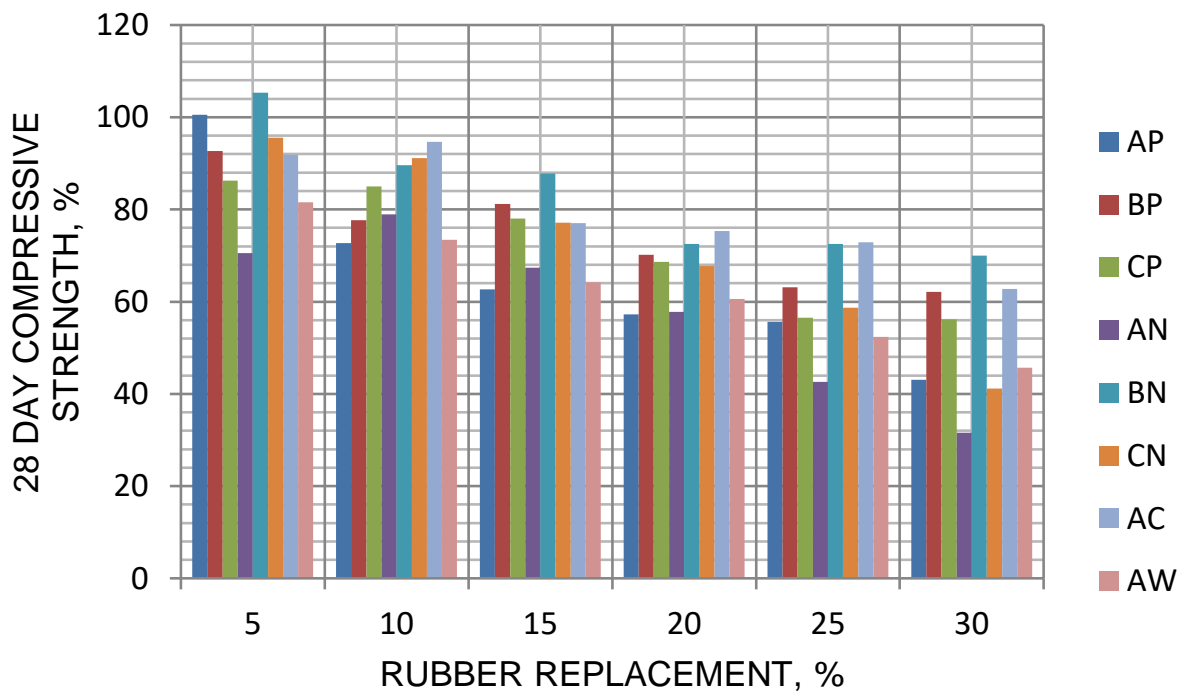

Figure 10. Effect of rubber aggregate substitution on compressive strength of 28 day concrete relative to control samples

Figure 10 confirms the majority of data from figure 9 as being strongly representative of the actual decline in compressive strength relative to each batches the control samples at 28 days testing. What is more apparent is the negligible increase in compressive strength for A5P. Due to the increase in compressive strength being as small as $0.49 \%$, one can not confidently state that $5 \%$ natural aggregate replacement by coarse rubber will have any noticable benefits to the concrete. However, B5N is noted to have a increase in compressive strength of $5.3 \%$. Whilst this is still negligible, the reduction in compressive strength relative to increased percentages of fine aggregate replacement is consistent for this series of data. Fine rubber treated with 
$\mathrm{NaOH}$ was on average approxiamtely $8.4 \%$ stronger at all 28 day tests than its plain counterparts. Bearing in mind the batch BP showed an increase in compressive strength at 7 days testing of approxiamtely $1 \mathrm{Mpa}$ and only a minor decrease of $0.38 \mathrm{Mpa}$ at 14 days, one could conclude that the increase in compressive strength for $\mathrm{B} 5 \mathrm{~N}$ at 28 days is likely to be quantifiable. Furthermore whilst $\mathrm{NaOH}$ treated coarse rubber had in general a negative effect when compared to plain coarse rubber, the use of $\mathrm{NaOH}$ on fine rubber had a positive effect. This is explained as a result of the increased surface area of the fine rubber aggregates relative to the same mass of coarse aggregates. This results in more surface contact with the cement and hence an increase in the positive effects of the $\mathrm{NaOH}$ surface treatment ( $\mathrm{Li}$ et al. 2004).

When comparing the compressive strength of concrete using plain rubber aggregates as a volumetric replacement of its natural aggreagates, the highest strength obtained was from the replacement of fine rubbers whilst coarse rubbers proved to be the weakest. This indicates that the inclusion of coarse rubber aggregates in $\mathrm{CP}$ and $\mathrm{CN}$ limited its compressive strength to below that of BP, whilst remaining higher than AP. When comparing A10P to $\mathrm{C} 20 \mathrm{P}$, there is only a $4.09 \%$ reduction in strength, and a $6.45 \%$ reduction in strength between $\mathrm{A} 15 \mathrm{P}$ and $\mathrm{C} 30 \mathrm{P}$. This reduction in strength is relitively small considering a $10 \%$ and $15 \%$ respective increase fine rubber content. With a reduction in strength of only $5.97 \%$ between B30P and C30P, this mix is still a viable option due to the fairly minimal reduction in compressive strength, but a sizeable increase in rubber content.

\section{CONCLUSIONS}

For plain rubber aggregate, the least reduction in compressive strength was obtained when using fine rubbers. CP is recommended for maximising rubber usage due to low reductions in strength relative to $\mathrm{BP}$ whilst utilising $28 \%$ more rubber due to its replacement of both fine and coarse rubber aggregates.

Water washing rubber aggregates did not prove beneficial to the compressive strength of rubberised concrete utilising coarse rubber aggregate. Any benefit that may have come from removing surface contaminants would be negligible enough to be undermined by potential increased water content from the surface of the washed rubbers.

One can conclude that the best performing rubberised concrete using coarse aggregate was cement paste coated rubber (AC), displaying an increase in compressive strength of almost $20 \%$ at a rubber content of $30 \%$ volume of coarse aggregate when compared to plain coarse rubber (AP). This can be attributed to increased compatibility in stiffness between rubber and cement paste, corresponding with previous findings such as Pocklington et al. 2015.

The best performing mix utilising fine rubber aggregate was that of sodium hydroxide treated fine rubber aggregate $-\operatorname{mix} \mathrm{BN}$. This is can be attributed to enhanced 
hydrophilic properties of rubber due to the treatment with $\mathrm{NaOH}$ resulting in reduced negative effects of the rubber on the hydration process of the cement in the concrete matrix corresponding to similar findings of $\mathrm{Lu}$ et al. 2007. The treatment of coarse rubber aggregates with $\mathrm{NaOH}$ is not recommended.

Concrete cubes at strength class $\mathrm{C} 30$ can comfortably be achieved using either Cement paste coated coarse rubber $(\mathrm{AC})$ or Sodium hydroxide treated fine rubber $(\mathrm{BN})$ at replacement levels of up to $25 \%$ by volume of natural aggregates. This is supportive of similar findings mentioned by Elchalakani M. 2015.

\section{REFERENCES}

ATAHAN, A, SEVIM, U (2008), Testing and comparison of concrete barriers containing shredded waste tire chips, Materials Letters, No.62, pp. 3754-3757

ELCHALAKANI M (2015), High strength rubberized concrete containing silica fume for the construction of sustainable road side barriers, Structures 1, p 20-38

ELDIN, N, SENOUCI, A (1993), Rubber-tyre particles as concrete aggregate, Journal of Materials in Civil Engineering Vol.5, No.2, pp. 478-496

ELDIN, N, SENOUCI, B (1994), Measurement and prediction of the strength of rubberised concrete, cement \& Concrete Composites, Vol. 16, pp.287-298

GANJIAN, E, KHORAMI, M, MAGHSOUDI, A A, (2009), Scrap-tyre-rubber replacement for aggregate and filler in concrete, Construction and Building Materials, vol. 23, No. 5, pp 1828-1836.

GESOGLU, M, GUNEYISI, E, KHOSHNAW, G, IPEK (2014), S, Abrasion and freezing-thawing resistance of pervious concretes containing waste rubbers, Construction and Building Materials, No.73, pp.19-24

KHALOO, A R, DEHESTANI, M, RAHMATABADI, P. (2008) Mechanical properties of concrete containing a high volume of tire-rubber particles, Waste Management, vol. 28, pp 2472-2482.

KHATIB, Z, BAYOMY, F, Rubberised Portland Cement Concrete (1993), Journal of Materials in Civil Engineering, Vol.11, No.3, pp.206-213

LI, G, STUBBLEFIELD, M A, GARRICK, G, EGGERS, J, ABADIE, C, HUANG, B. (2004), Development of waste tyre modified concrete, Cement and Concrete Research, Vol. 34, pp 2283-2289.

LIU, F, CHEN, G, LI, L, GUO, Y (2012), Study of impact performance of rubber reinforced concrete, Construction and Building Materials, No.36, pp. 604-616 
LU, L H C C, CHANG, J, LEE, M T. (2007), Use of waste rubber as concrete additive, Waste Management \& Research, Vol. 25, pp 68-76.

MEMON, F A, NURUDDIN M F, KHAN A, SHAFIQ N, AYUB T. (2013), Effect of sodium hydroxide concentration on fresh properties and compressive strength of self-compacting geopolymer concrete, Journal of Engineering Science and Technology, Vol. 8, No. 1, pp 44-56.

MORONEY C (2003), The use of granulated rubber from used tyres in concrete, $\mathrm{PhD}$ thesis, University of Dundee, Uk,

POCKLINGTON, I, KEW, H, DONCHEV, T, LIMBACHIYA, M. (2015), Compressive strength and mix behaviour of rubberised concrete, International conference of composite materials 20.

REDDY, V V, RAO, H S, JAYAVEERA, K N. (2006), Influence of strong alkaline substances (sodium carbonate and sodium bicarbonate) in mixing water on strength and setting properties of concrete, Indian Journal of Engineering \& Materials Sciences, Vol. 13, pp 123-128. 